\title{
Practical aspects of the investigation of disorders of carbohydrate metabolism
}

\author{
VINCENT MARKS
}

From the Area Laboratory at West Park Hospital, Epsom, Surrey

The first requirement for the investigation of clinical disorders of carbohydrate metabolism is a simple, accurate and reliable micro-method for measuring glucose concentration in biological fluids. Since 1913, when the first practicable methods became available, many techniques have been used, but most are non-specific because they measure, in addition to glucose, other sugars and other reducing substances (generically called saccharoids) that are present to a variable extent in blood.

Isles (1967) has drawn attention to the continued use of non-specific methods even in critical studies of blood glucose levels. The Folin-Wu (1920) technique is still very widely used (Skendzel and Muelling, 1967), especially in small laboratories in the USA, even though it gives blood 'glucose' levels whose saccharoid content may range as high as $50 \mathrm{mg} / 100 \mathrm{ml}$ even in normoglycaemic subjects. The Hagedorn-Jensen method (1923) is equally inaccurate (Hjelm, 1966). The best of the reductiometric methods, eg, the Nelson-Somogyi (1944) technique and the AutoAnalyzer modification of the Hoffman technique (1937), and the best chromogenic techniques, $e g$, the toluidine blue procedure (Hyvarinen and Nikkila, 1962), give a closer approximation to the true glucose content of blood (Watson and Stevenson, 1963). Nevertheless serious errors may still occur in hypoglycaemic states or when galactose or fructose is present.

Many methods use glucose-oxidase which is almost specific for $\beta$-glucose. The only other sugar with which it reacts to any appreciable degree is 2-deoxy-d-glucose, a synthetic hexose sometimes used experimentally or clinically in tests of vagal or adrenal medullary function. Glucose-oxidase may be used in a variety of ways, the commonest being in combination with peroxidase and a chromogenic hydrogen donor.

Glucose $+\mathrm{O}_{2} \frac{\text { glucose-oxidase }}{\text { peroxidase }}$ Gluconic acid $+\mathrm{H}_{2} \mathrm{O}_{2}$

$\mathrm{H}_{2} \mathrm{O}_{2}+$ chromogen $\stackrel{\text { peroxidase }}{\longrightarrow}$ Coloured product

The extreme specificity of glucose-oxidase for glucose should not obscure the fact that its use does not ipso facto confer specificity or accuracy upon any technique in which it is used (Fales, Russell, and Fain, 1961; Hjelm, 1966). For example, nonglucose reducing substances in blood may also interfere with chromogen formation in linkedenzyme glucose-oxidase techniques unless removed by precipitation. Neutral precipitants, which must be added in the correct sequence (Middleton and Griffiths, 1957; Welch and Danielson, 1962), are more suitable for this purpose than acid precipitants (Hansen, 1962). The latter have the additional disadvantage (Schulthess, 1966) that under certain conditions and in the presence of oxyhaemoglobin (Lemberg, 1942) they may produce peroxides which are themselves capable of participating in the second, peroxidase-mediated reaction.

The two most popular chromogens, o-tolidine and o-dianisidine, have recently been designated potential carcinogens (HMSO, 1967), and substitutes have been sought. Guaiacum, which is not carcinogenic, has been found more sensitive (Hill, 1965; Morley, Dawson, and Marks, 1968), and has the added advantage that uric acid does not interfere with colour formation. This is especially valuable when proteins are removed by dialysis, eg, in AutoAnalyzer techniques, or when plasma is added directly to the enzyme reagent without prior protein precipitation (a procedure which enables the glucose content of as little as $10 \mu 1$ of plasma to be measured simply and accurately). Though many other methods utilizing glucose-oxidase have been devised for measuring blood glucose, some of them extremely sophisticated (Kadish, Litle, and Sternberg, 1968; Simon, Christian, and Purdy, 1968), none are simpler and few are as sensitive and precise as the guaiacum method, though some are particularly amenable to automation and may find favour on that account.

A disadvantage common to all glucose-oxidase methods is that the enzyme preparations used may be impure initially and may deteriorate on keeping. Many commercial preparations are in fact contaminated with additional enzymes (White and Subers, 
1961; Blecher and Glassman, 1962; Rerup and Lundquist, 1967), and these may reduce the specificity of the method. Fortunately this does not cause significant error in most clinical measurements but must be taken into account in certain experimental situations in which glucose is measured in the presence of high concentrations of other sugars or sugar polymers.

There are other ways in which specificity, coupled in some cases with extreme sensitivity and precision, can be achieved. These include the use of high resolution column chromatography (Jolley, Warren, Schonfield, Scott, and Freeman, 1968), gas liquid chromatography (Wells, Chin, and Weber, 1964), and methods which use enzymes other than glucoseoxidase, eg, either hexokinase or acylphosphateglucose transferase coupled with glucose-6-phosphate dehydrogenase and NADP as indicator (Bergmeyer and Moellering, 1966).

Glucose + ATP $\stackrel{\text { Hexokinase }}{\longrightarrow}$ glucose-6-phosphate + ADP

or

Glucose + acylphosphate $\frac{\begin{array}{c}\text { Acylphosphate- } \\ \text { glucose transferase }\end{array}}{\text { 6-phosphate }+ \text { acyl acid }}$

Glucose-6-phosphate + NADP G-6-P dehydrogenase 6-phosphogluconate + NADPH

All yield more or less equivalent results, both among themselves and in comparison with the better glucose-oxidase techniques, but because of their complexity or cost none has yet found general acceptance in clinical laboratories.

From the foregoing discussion it is obvious that none of the currently available methods for measuring blood glucose is best under all possible circumstances. It is equally clear that many of the methods retained in use, either because of familiarity or innate conservatism, are long overdue for retirement. The method currently used in our laboratory is a glucose-oxidase-peroxidase-guaiacum technique (Morley et al, 1968), but in some situations the toluidine-blue technique (Hyvarinen and Nikkila, 1962) may be preferable.

\section{GLUCOSE IN URINE}

Traditionally glucose is detected and measured in urine by its capacity to reduce alkaline copper solutions. The sensitivity of most of the methods is such that 'glucose' is not detected unless present in a concentration greater than $100 \mathrm{mg} / 100 \mathrm{ml}$, a figure seldom likely to be exceeded in normal healthy individuals. The introduction of enzymeimpregnated strips capable of detecting glucose in some urines at concentrations as low as 20 to $30 \mathrm{mg} / 100 \mathrm{ml}$ increased enormously the number of people with demonstrable glucosuria. With even more sensitive techniques everyone can be shown to have some degree of glucosuria and it has even been suggested that reduction below $2 \mathrm{mg} / 100 \mathrm{ml}$ of urine is an indication of bacilluria (Schersten and Tibbling, 1967).

It has been proposed by Marks and Samols (1968) that excessive or significant glucosuria should be defined as the excretion of more than $150 \mathrm{mg}$ of glucose per day. In most cases this is revealed by tests for reducing sugars, such as Benedict's or the Clinitest, which have the advantage, not possessed by enzyme-impregnated strips, that they also detect non-glucose melliturias. This is especially important in infants in whom detection of non-glucosereducing substances in the urine may provide the first clue to the nature of their illness (eg, galactosaemia, or hereditary fructose intolerance). Therefore urine should be screened for sugars by reductiometric methods and not with enzyme-impregnated strips despite their simplicity in use. If reducing substances are found, an enzyme strip may then be used to test whether glucose is present. It should be remembered that the shelf life of such strips is limited and that their deterioration may lead to false-negative results.

There are few clinical indications for accurate urine glucose measurements other than for research or as part of the Joplin procedure for latent diabetes (Joplin and Wright, 1968). When required, such measurements can be made after suitable preparation of the urine by the same procedures as are used for blood, with the reservation that reductiometric methods should not be used.

\section{OTHER SUGARS OF CLINICAL IMPORTANCE}

Sugars other than glucose normally occur in blood and urine only in trace amounts. Their measurement may require the use of sophisticated chromatographic or enzymatic techniques. Fortunately fructose and galactose, both of which are used clinically in various test procedures and may also occur in high concentrations in blood in certain rare diseases, are amenable to measurement by simpler means. Currently a popular method for measuring the concentration of galactose in blood and urine uses the enzyme galactose-oxidase (Cooper, Smith, Bacila, and Medina, 1959; Avigad, Amaral, Asensio, and Horecker, 1962). 


$$
\begin{aligned}
& \text { Galactose }+\mathrm{O}_{2} \frac{\text { Galactose-oxidase }}{\text { Galacto-hexodialdose }+\mathrm{H}_{2} \mathrm{O}_{2}} \\
& \mathrm{H}_{2} \mathrm{O}_{2}+\text { chromogen } \stackrel{\text { Peroxidase }}{\rightarrow} \text { Coloured product }
\end{aligned}
$$

Though this enzyme is less specific for galactose than glucose-oxidase is for glucose (Avigad et al, 1962), none of the other substrates for galactoseoxidase normally occurs in blood or urine. In most techniques galactose-oxidase is used in conjunction with peroxidase and o-dianisidine (Roth, Segal, and Bertoli, 1965; Ford and Haworth, 1964; Hjelm, 1966). A lack of linearity in the calibration curve at blood galactose concentrations below $20 \mathrm{mg} / 100 \mathrm{ml}$ can be overcome by adding a small amount of galactose (equivalent to a blood galactose concentration of $30 \mathrm{mg} / 100 \mathrm{ml}$ ) to the buffer which serves both as the blank and the diluent in which the galactose standards and blood samples are diluted before measurement. Attempts in our laboratory to substitute the noncarcinogenic chromogen guaiacum for o-dianisidine have been unsuccessful. Galactose-oxidase-impregnated strips (Dahlqvist, 1966) suitable for detecting galactose in urine are now available commercially. A further technique for measuring galactose in biological fluid uses galactose dehydrogenase (Boeringer and Soehne, 1967). This is said to be particularly valuable where a high degree of specificity for galactose is required, as in the analysis of tissues for their carbohydrate content.

Measurements of galactose in blood either by galactose-oxidase or by galactose dehydrogenase have an accuracy similar to that obtained for glucose in blood using a glucose-oxidase-chromogen method (Watson, 1963) but, because of its extreme simplicity and ease of performance, and in spite of the relatively high cost of the enzyme at the present time, the galactose-oxidase method is preferred, especially when the number of specimens to be examined is small.

For measuring fructose in blood we prefer to use the indol-acetic acid technique (Henry, 1964). Nevertheless, although the method is both practicable and sufficiently specific for clinical use, serum blanks equivalent to $5 \mathrm{mg} / 100 \mathrm{ml}$ of fructose are not uncommon, and for the most accurate analytical work a chromatographic or enzymatic technique must be used.

\section{DYNAMIC TESTS OF CARBOHYDRATE METABOLISM}

In practice, single measurements of glucose concentration in blood are of limited clinical value.
They are useful for following the response to treatment in cases of diabetes mellitus and are indispensable for the diagnosis of some forms of spontaneous hypoglycaemia, but except in florid diabetes observation of the homeostatic response to a standard stimulus generally yields more diagnostic information. The number of tests designed to measure various aspects of homeostatic control is large and growing rapidly. Those in general use up to 1964 have been reviewed by Foa (1966).

The greatest change in clinical practice in the past five years has been the increasing frequency with which more than one parameter of carbohydrate metabolism is measured during any provocative procedure. Examples are the measurement of plasma non-esterified fatty acids, growth hormone, and insulin concentrations during glucose tolerance tests. So far these additional measurements have not found widespread clinical application except in the differential diagnosis of spontaneous hypoglycaemia, but have nevertheless provided valuable information on the pathogenesis of disturbed glucose homeostasis in various diseases.

\section{ORAL GLUCOSE TOLERANCE TEST}

The oral glucose tolerance test is still the commonest dynamic test of glucose homeostasis despite the numerous variables (Table I) which affect the test

TABLE I

FACTORS INFLUENCING ORAL GLUCOSE TOLERANCE TEST

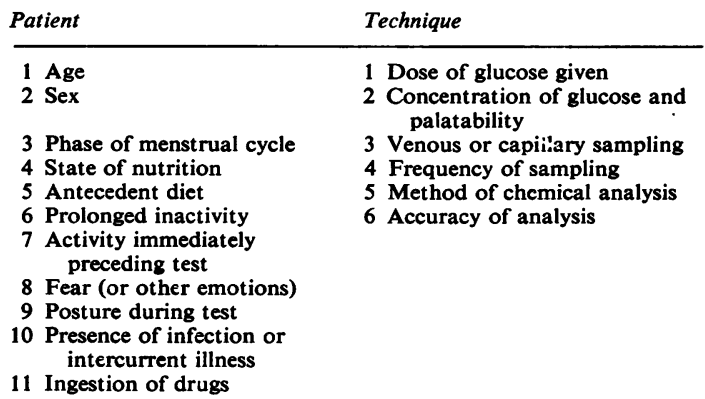

and complicate its interpretation under ordinary clinical conditions. The substitution of a palatable liquid glucose preparation for powdered dextrose, and the use of indwelling plastic venous cannulae for collecting blood instead of multiple punctures make the oral glucose tolerance test more acceptable to patients. However, in the majority of cases it is doubtful whether formal oral glucose tolerance testing, as usually performed, provides any more clinically useful information than measurement of the blood glucose concentration two hours after 
a meal containing at least $50 \mathrm{~g}$ carbohydrate (West, Wulff, Reigel, and Fitzgerald, 1964; West, 1966). It may, however provide reassurance to the investigator.

From time to time more or less rigid criteria for the interpretation of oral glucose tolerance tests have been proposed, but none of the proposals has received universal recognition. In general too little allowance has been made in defining the 'normal range' for the many variables that influence the result, so that under practical clinical conditions it is seldom possible to compare like with like. A selection of criteria proposed in the past decade by 10 different groups of workers is given in a recent review by Joplin and Wright (1968) to which reference should be made for more detailed discussion.

The prolonged oral glucose tolerance test (five to six hours) is traditionally employed for the diagnosis of essential reactive or 'functional' hypoglycaemia, although lack of reliable information on what constitutes the 'normal' response makes meaningful interpretation virtually impossible at the present time. Many normal healthy subjects display 'reactive hypoglycaemia' during prolonged oral glucose tolerance tests; and blood glucose concentrations as low as $30 \mathrm{mg} / 100 \mathrm{ml}$, with or without symptoms of hypoglycaemia, are not uncommon, especially when $100 \mathrm{~g}$ rather than $50 \mathrm{~g}$ glucose is administered. In a group of 51 patients referred to this laboratory for oral glucose tolerance tests, unselected except that subjects with overt diabetes were excluded, venous blood glucose levels fell below $50 \mathrm{mg} / 100 \mathrm{ml}$ in $38(75 \%)$ at some time during the five hours following the ingestion of $100 \mathrm{~g}$ glucose. In 22 $(42 \%)$ the blood glucose concentration fell below $40 \mathrm{mg} / 100 \mathrm{ml}$, thus fulfilling the diagnostic criteria for 'reactive hypoglycaemia'. It is still undetermined whether such apparently normal individuals, who in the majority of cases had a normal two-hour glucose tolerance, should be considered early latent diabetics (Faludi, Bendersky, and Gerber, 1968; Schless, 1968) but there is clearly no justification for considering them as victims of 'essential reactive hypoglycaemia' since they experience spontaneously none of the symptoms which are described as characteristics of this illness (Marks and Rose, 1965) but which are equally common-or commoner-in patients in whom there is little or no hypoglycaemic rebound during oral glucose tolerance tests.

Harrison (1957) has drawn attention to the fallacy of using the oral glucose tolerance test to diagnose malabsorption because it is impossible to have a curve flatter than that which may occur in many normal, healthy young subjects. On the other hand, after partial gastrectomy when absorption of many foodstuffs is often seriously impaired, the hyperglycaemic phase of the oral glucose tolerance test is more often exaggerated than diminished, because rapid stomach emptying increases the rate at which glucose is made available for intestinal absorption.

\section{INTRAVENOUS GLUCOSE TOLERANCE TEST}

In order to improve the reproducibility and facilitate the interpretation of glucose tolerance tests, attempts have been made to circumvent unpredictable alimentary factors by administering glucose intravenously. These have not been altogether successful: first, because the alimentary tract is now recognized to be not merely a mechanism by which nutrients gain entrance to the body, but also a participant in the regulation of their metabolism through various hormonal factors (McIntyre, Holdworth, and Turner, 1965); secondly, because many of the variables that make interpretation of the oral glucose tolerance test so difficult still complicate the intravenous glucose test. Furthermore, there is no agreement as to how the result should be presented. We, in common with most other workers in Britain and elsewhere, use the method of analysis popularized by Conard and his co-workers in Belgium (Conard, 1955; Bastenie and Conard, 1957; Franckson, Ooms, Bellens, Conard, and Bastenie, 1962) even though its theoretical basis is no longer completely acceptable (Samols and Marks, 1965). In this way the glucose tolerance is expressed numerically as a single figure, the glucose assimilation coefficient $(\mathbf{K g})^{1}$, which is well suited to comparative studies or for following progress or change due to treatment in individual subjects. With a standard intravenous injection of $25 \mathrm{~g}$ glucose given within two minutes, a glucose assimilation coefficient of less than 1.0 is indicative of impaired glucose tolerance (Lundbaek, 1962). The upper limit of normal, on the other hand, is poorly defined so that, like the oral glucose tolerance test, the rapid intravenous glucose tolerance test cannot be used to diagnose 'increased' glucose tolerance. Contrary to former belief the intravenous glucose tolerance test is virtually useless for the detection and differential diagnosis of spontaneous hypoglycaemia.

\section{OTHER TESTS OF GLUCOSE HOMEOSTASIS}

Space does not permit even brief discussion of the many new tests which have been introduced to ${ }^{1} K_{\mathrm{g}}=\frac{\log _{\mathrm{e}}^{2}}{\mathrm{t} / \mathrm{2}} \times 100$ where $\mathrm{t} / 2$ is the time taken for the blood glu-
cose concentration to fall to one half its value. 
(a) Cortisone-glucose tolerance

(b) Prednisone tolerance Intravenous tolbutamide

Glucagon

Glucose-glucagontolbutamide Alcohol infusion Ketogenic provocation L-leucine

Insulin sensitivity
Originally described for detection of 'pre-diabetes', now used to detect 'latent diabetes', in patients with normal regular glucose tolerance test

Introduced as test for diabetes but more often employed for detection of hypoglycaemia; potentially dangerous

(a) Useful test for recognition and differential diagnosis of spontaneous hypoglycaemia; (b) valuable in investigation of glycogen storage disease Procedure for measuring maximal insulin secretory capacity of $\beta$-cells of pancreas

Test of hepatic gluconeogenesis

Used for diagnosis of ketogenic hypoglycaemia in children (a) Detection of leucine-sensitive type of idiopathic hypoglycaemia in childhood; $(b)$ in the differential diagnosis of hypoglycaemia in adults Measures exogenous insulin sensitivity and homeostatic response to induced hypoglycaemia (a) Fajans and Conn (1965)

(b) Joplin and Wright (1968) Creutzfeldt and Czyzyk (1967)

(a) Marks and Samols (1968b). (b) Sokal, Lowe, and Sarcione (1962) Ryan, Nibbe, and Schwartz (1967)

Arky and Freinkel (1966)

Colle and Ulstrom (1964)

(a) Cornblath and Schwartz (1966)

(b) Marks and Rose (1965)

Cornblath and Schwartz (1966)

Greenwood, Landon, and Stamp (1966) assess more or less specific aspects of homeostatic function in patients suspected of suffering from disorders of carbohydrate metabolism. Some of the more important are listed in Table II, together with references selected on the basis of ready availability and general applicability rather than priority.

\section{MEASUREMENT OF HORMONES IN BLOOD}

During the past decade many of the hormones most intimately concerned with the regulation of glucose homeostasis have become amenable to accurate and specific measurement in blood (Gray and Bacharach, 1967); in the case of insulin and growth hormone the reagents necessary are available commercially. ${ }^{1}$

Insulin assays are invaluable in the differential diagnosis of spontaneous hypoglycaemia and for the elucidation of the pathogenesis of the various types of hyperglycaemia, but so far, their clinical usefulness in other aspects has been limited (Marks, 1969).

Growth hormone assays have contributed disappointingly little to our understanding of clinical disorders of carbohydrate metabolism except to confirm that inappropriate and excessive growth hormone secretion may precipitate a diabetic state in susceptible subjects, ${ }^{2}$ and that growth hormone deficiency is a rare, though interesting, cause of spontaneous hypoglycaemia.

Accurate and meaningful measurement of glucagon in peripheral venous blood has proved more difficult than was originally believed (Marks, 1969) and at the present time its clinical usefulness is confined to confirmation of hyperglucagonaemia (McGavran, Unger, Recant, Polk, Kilo, and Levin, 1966) caused by metastic glucagonoma, the clinical

- Welcome Research Laboratories, Langley Court, Beckenham, Kent. 2 See contribution by Dr Taylor, ED. features of which are still poorly defined due to the very small number of cases that have so far been reported.

\section{CONCLUSION AND SUMMARY}

Critical reappraisal of the significance of the various 'glucose tolerance tests' is long overdue. For many years they have been used by physicians and pathologists alike as a concession to 'scientific investigation' in patients suspected of suffering from some metabolic derangement. However it is evident that more specific tests of the functional integrity of glucose homeostasis are needed, for increasing experience with such dynamic tests in a wide range of clinical disorders reveals serious limitations to their clinical usefulness. Many, though capable of yielding valuable information under strictly controlled experimental conditions (such as usually obtain in the laboratories of the investigators who originally described them) are so subject to variation as frequently to be almost uninterpretable in individual cases. Multiple measurements of several parameters are needed to increase their specificity and consequently their clinical value. Only in this way will it be possible to differentiate the many different diseases which, because they share the common feature of impaired glucose tolerance, at present masquerade under the cloak of diabetes mellitus.

\section{REFERENCES}

Arky, R. A., and Freinkel, N. (1966). New Engl. J. Med., 274, 426. Avigad, G., Amaral, D., Asensio, C., and Horecker, B. L. (1962) J. biol. Chem., 237, 2736.

Bastenie, P. A., and Conard, V. (1957). Rev. franc. Etud. clin. biol., $2,223$.

Bergmeyer, H. U., and Moellering, H. (1966). Clin. chim. Acta, $14,74$.

Blecher, M., and Glassman, A. B. (1962). Anal. Biochem., 3, 343.

Boehringer, C. F., \& Soehne GmbH (1967). Galactose Biochemical Test Combination. 
Colle, E., and Ulstiom, R. A. (1964). J. Pediat., 64, 632.

Conard, V. (1955). Acta gastroent. belg., 18, 655, 727 and 803.

Cooper, J. A. D., Smith, W., Bacila, M., and Medina, H. (1959). J. biol. Chem., 234, 445 .

Cornblath, M., and Schwartz, R. (1966). Disorders of Carbohydrate Metabolism in infancy. Saunders, Philadelphia.

Creutzfeldt, W., and Czyzyk, A. (1967). Acta diabet. lat., 4, On the intravenous tolbutamide test. Il Ponte, Milano.

Dahlqvist, A. (1966). Scand. J. clin. Lab. Invest., 18, suppl. 92, 101.

Fajans, S. S., and Conn, J. W. (1965). In On the Nature and Treatment of Diabetes, edited by B. S. Leibel and G. A. Wrenshall, p. 641. Excerpta Medica Foundation, Amsterdam.

Fales, F. W., Russell, J. A., and Fain, J. N. (1961). Clin. Chem., 7, 389.

Faludi, G., Bendersky, G., and Gerber, P. (1968). Ann N.Y. Acad. Sci., 148, 868.

Foa, P. P. (1966). In The Handbook of Experimental Pharmacology vol. $\mathrm{xvi} / 15, \mathrm{p}$. 1. Springer, Berlin.

Folin, O., and Wu, H. (1920). J. biol. Chem., 41, 367.

Ford, J. D., and Haworth, J. C. (1964). Clin. Chem., 10, 1002.

Franckson, J. R. M., Ooms, H. A., Bellens, R., Conard, V., and Bastenie, P. A. (1962). Metabolism, 11, 482.

Gray, C. H., and Bacharach, A. L. (1967). Hormones in Blood, 2nd ed., vol. 1. Academic Press, London.

Greenwood, F. C., Landon, J., and Stamp, T. C. B. (1966). J. Clin. Invest., 45, 429.

Hagedorn, H. C., and Jensen, B. N. (1923). Biochem. Z., 135, 46.

Hansen, O. (1962). Scand. J. clin. Lab. Invest., 14, 651.

Harrison, G. A. (1957). Chemical Methods in Clinical Medicine, 4th ed. p. 174. Churchill, London.

Henry, R. J. (1964). Clinical Chemistry Principles and Technics, p. 686. Hoeber, New York.

Hjelm, M. (1966). Scand. J. clin. Lab. Invest., 18, suppl. 92, 85.

Hill, J. B. (1965). J. appl. Physiol., $20,749$.

Hoffman, W. S. (1937). J. biol. Chem., 120, 51.

H.M.S.O., London (1967). Statutory Instrument No. 879. Carcinogen Substances Regulations.

Hyvärinen, A., and Nikkilä, E. A. (1962). Clin. chim. Acta, 7, 140

Isles, T. E. (1967). Lancet, 2, 1043.

Jolley, R. L., Warren, K. S., Schonfeld, E., Scott, C. D., and Freeman, M. L. (1968). Clin. Chem., 14, 804.

Joplin, G. F., and Wright, A. D. (1968). In Carbohydrate Metabolism and its Disorders, edited by F. Dickens, P. J. Randle, and W. J. Whelan, vol. 2. p. 1. Academic Press, London.
Kadish, A. H., Litle, R. L., and Sternberg, J. C. (1968). Clin. Chem., $14,116$.

Lemberg, R. (1942). Aust.J. exp. Biol. med. Sci., 20, 111.

Lundbaek, K. (1962). Brit. med.J., 1, 1507.

McGavran, M. H., Unger, R. H., Recant, L., Polk, H. C., Kilo, C. and Levin, M. E. (1966). New Engl.J. Med., 274, 1408.

McIntyre, N., Holdsworth, C. D., and Turner, D. S. (1965). J. clin. Endocr., 25, 1317.

Marks, V. (1969). Brit. J. hosp. Med., in press.

- , and Rose, F. C. (1965). Hypoglycaemia. Blackwell Scientific Publications, Oxford.

Disorders, edited by F. Dickens, P. J. Randle, and W. J. Whelan, vol. 2. p. 337. Academic Press, London.

- (1968b). J. clin. Path., 21, 346.

Middleton, J. E., and Griffiths, W. J. (1957). Brit. med. J., 2, 1525.

Morley, G., Dawson, A., and Marks, V. (1968). Proc. Ass. clin. Biochem., 5, 42.

Nelson, N. (1944). J. biol. Chem., 153, 375.

Rerup, C., and Lundquist, I. (1967). Acta pharmacol. (Kbh), 25, 41.

Roth, H., Segal, S., and Bertoli, D. (1965). Anal. Biochem., 10, 32.

Ryan, W. G., Nibbe, A. F., and Schwartz, T. B. (1967). Lancet, 1, 1255

Samols, E., and Marks, V. (1965). Ibid., 1, 462.

Scherstén, B., and Tibbling, G. (1967). Clin. chim. Acta, 18, 383.

Schless, G. L. (1968). Brit. J. hosp. Med., 1, 389.

Schult hess von, F. R. (1966). Helv. med. Acta, 33, 59

Simon, R. K., Christian, G. D., and Purdy, W. C. (1968). Clin. Chem., $14,463$.

Skendzél, L. P., and Muelling Jr., R. J. (1967). New Engl. J. Med., $277,180$.

Sokal, J. E., Lowe, C. U., and Sarcione, E. J. (1962). Arch. intern. Med., 109, 612 .

Watson, D. (1963). Anal. Biochem., 5, 260.

- , and Stevenson, M. E. K. (1963). Aust. J. exp. Biol. med. Sci., $41,211$.

Welch, N. L., and Danielson, W. H. (1962). Amer. J. Clin. Path., 38, 251.

Wells, W. W., Chin, T., and Weber, B. (1964). Clin. chim. Acta, 10,352 .

West, K. M. (1966). Arch. intern. Med., 117, 187.

—, Wulff, J. A., Reigel, D. G., and Fitzgerald, D. T. (1964). Ibid., 113,641 .

White, J. W., Jr., and Suters, M. H. (1961). Anal. Biochem., 2, 380. 